\title{
Türkiye Türkçesinde ve Azerbaycan Türkçesinde "Su" Unsurlu Atasözlerinin Gramer Özellikleri
}

\begin{abstract}
Ahmet Öksüz ${ }^{1}$
$\ddot{O} \mathbf{z}$

İnsanın yaşam tarzı, tarihi, kültürü, hayata bakış açısı dilde yansıtılır. Atalarımızdan bize aktarılan ve anların üzün süre gözlemleyip bir sonuca vararak öğüt ve nasihat şeklinde aktarmış oldukları özlü sözlerdir. Atasözleri değişik dillerde farklı terimlerle telaffuz edilmiştir; Türkçede ise Kaşkarlı Mahmut sav şeklinde ifade ederken daha sonraları Osmanlı Türkçesinde ise darbımesel veya durûb-i emsal kelime grubuyla ifade edilmiştir. Günümüz Türkçesinde ise atasözü şeklinde söylenmektedir. Azerbaycan Türkçesinde ise Atalar sözü terimiyle ifade edilmektedir. Atasözleri toplumda yaşanan olaylardan çıkarılması gereken dersleri bir nasihat bir öğüt şeklinde kısaca anlatır, dile getirir. O nedenle atasözlerini deyimlerden ayıran en önemli tarafı atasözlerinin bir yargı bildirmesidir. $\mathrm{Bu}$ ögüt bütün toplumu kapsar ve her zaman doğruya ve iyiye yönlendirir. Diğer taraftan değişik Türk toplulukları kendi atasözlerini toplamışlar ve üzerinde dil çalışmaları yapmışlardır. Bu bakımdan atasözleri ve deyimlerin incelenmesi özel önem taşımaktadır. Türkiye ve Azerbaycan tarihten bu güne hem dilde hem de kültürde birlikteliği sağlamış iki devlettir. Aynı dili konuşmamızın yanında farklı komşuluk ilişkilerine sahip olmamız ve farklı kültürlerden etkilenmemiz nedeni ile hem dilde hem de kültürde azda olsa farklılıklar vardır. Bu farklılıklar atasözlerinde de görülmektedir.
\end{abstract}

Biz bu araştırmamızda iki Türkçede su ile ilgili söylenmiş atasözlerinin gramer özellikleri üzerinde durarak farklı ve benzer yanları nelerdir; bunu ortaya koymaya çalışacağı.

\footnotetext{
${ }^{1}$ Karabük Üniversitesi Edebiyat Fakültesi Öğretim Üyesi.
} 
Anahtar kelimeler: Atasözleri, Türkiye Türkçesi, Azerbaycan Türkçesi, Türkçe gramer, Türk kültürü, Su kültürü, dil kültürü.

\title{
The Grammatical Features of the Word "Water" in the Proverbs of Turkey and Azerbaijan
}

\begin{abstract}
The lifestyle, history and culture of a nation are all reflected in the language. Proverbs are the aphorisms transferred to us from our ancestors and reflect their opinions giving counsels and advices gathered with their observation for a long time. Proverbs are expressed with different terms in different languages; Kashkarli Mahmud expressed as "sav" in Turkish, but later in Ottoman Turkish it is expressed as "darb-1 mesel" or "durûb-i emsal". While it is denoted as "atasözü" in today's Turkish language, it is told as "atalar sözü” in Azerbaijani. Proverbs tell us the lessons to be drawn from the events happened in the community in terms of an advice or a counsel briefly. Therefore the most important aspect of the proverbs that distinguishes them from other expressions is that a judgment is mentioned in a proverb. On the other hand, various Turkish communities have gathered their own proverbs and have several works done on them. In this regard, investigation of proverbs and idioms are of special importance. Turkey and Azerbaijan are the states that have provided the coexistence of both culture and language from history up to this time. Although we speak the same language, there are slight differences in both culture and language depending on having different neighborly relations and influence from the different cultures and languages. These differences are also seen in proverbs.

In this study, we will try to put forward different and similar aspects emphasizing the grammatical features of proverbs contain the word water in both languages.

Keywords: Proverbs, Turkish, Azerbaijani Turkish, Turkish grammar, Turkish culture, Turkish language.

\section{Giriş}

Dünya dilciliğinde paremioloji adlanan (paremioloji -Yunanca'da "eğitici fikir" anlamında kullanılan terimdir) kelime bilimi vardır. Atasözleri ve deyimler de eğitici tarafının ağır basması nedeniyle işte söz konusu bölümde de araştırılır. Dünya coğrafyasında en eski uygarlıklardan birine sahip olan büyük Türk milleti, ilk dönemden itibaren değişik bölgelere yayılarak zamanla zengin bir sözlü halk kültürü oluşmuştur.
\end{abstract}


Atasözleri ve deyimler bir ulusun yaşantısını, adet ve ananelerini, kültürünü, dilini, inancını tanıtan, bu değerleri ortaya koyan önemli kültür hazinelerinin önde gelenlerindendir. Mesel veya atasözü bir fikri savunmada, bir olayı, bir davranışı yorumlamada, yermede kullanılan etken bir dil aracıdır (Eyüboğlu, 1973). Mezmun ve gayesine göre zaman-mekan dâhilinde deyişmiş, cilalanmış, yeniden türemiş, hacmi son derece kısa olan, neticede fikri tutarlı ifade eden sözlerdir (Hekimov, 1986: 82). Her ulusun varoluşundan bu yana atasözleri ve deyimler o ulusa 1şık tutan, yol gösteren, bilgelik kaynağı olan ve öğütler veren altın sözlerdir. Farklı coğrafyalarda yaşayan halkların atasözlerinin hem şekil hem de anlam bakımından benzer olmasında, dil, din, kültür, ırk, coğrafya, sosyal ve medeni ilişkiler başta gelir (Xaliq, 2004: 7).

Her ulus hemen her konuda kendi atasözünü yaratmıştır ve her konuda söylenmiş atasözü vardır. İnsan hayatında suyun çok önemli olduğu inkar olunmaz bir gerçektir. Bu sebeple de suyun önemiyle ilgili birçok söylenmiş atasözleri vardır.

Türk dilinde son dönemlerde atasözleri ve deyimleri ile bağlı birçok çalışmalar yapılmışsa da atasözleri ve deyimlerin gramer özellikleriyle ilgili yapılan çalışmalar yeterli değildir. Örneğin, Ömer Asim Aksoy (Atasözleri ve Deyimler Sözlüğü, 1965); M. Ertuğrul Sarabaş1, ve İbrahim Minnetoğlu (Türkçe Deyimler Sözlüğü (2002)); E.Kemal Eyüboğlu On Üçüncü Yüzyıldan Günümüze Kadar Şiirde ve Halk Dilinde Atasözleri ve Deyimler, Türk Dil Kurumu tarafından yayımlanan (Bölge Ağızlarında Atasözleri ve Deyimler, I-II, Ankara, 1971) gibi araştırmalarda da frazeoloji ifadeler gereken leksikografi prensiplere mutabık olmasına rağmen soru işaretleri giderilememiştir. Azerbaycan dilciliğinde bu alanda çalışmalar yapılmıştır. Örneğin, H Zeynallı, Azerbaycan Atalar Sözü (Bakü, 1926); İ. Abbaslı, (2004). Atalar Sözü, Yusuf B. Kerimov- B. Şişmanoğlu, Atasözleri ve Özlü Sözler (Sofya 1960); Ülviye Mamedova (Azerbaycan ve İngiliz dillerindeki atasözleri ve deyimlerin anlam ve yapısal özellikleri, doktora tezi, 2013); İ. Hamidov (Azerbaycan-Rus atasözleri sözlüğü, Bakü, 2004), A. Hüseynzade: Atalarsözü (Bakü, 1985). Türkiye Türkçesinde atasözleriyle ilgili ilk çalışma yapan araştırmacılardan Ömer Asim Aksoy’dur. Aksoy, atasözleri ve deyimlerin gerçek anlamının yanında esas olarak mecazi anlamda kullanıldığını belirtmiştir.

Atasözleri ve deyimler dilbilgisinin sözcükbilim (leksikoloji) alt dalında incelenir. Sözcükbilim, dilin leksik sisteminin kelimeden, her şeyden önce, kendi yapısına göre farklı özel bir birimidir. Türkçede genel olarak kelime gruplarının bir kısmı, deyimler, atasözleri, darb-1 meseller gerçek anlamında değil başka bir anlamda yani, mecaz anlamı kazanmış şekilde kullanılır.

Bu çalışmamızda Türkiye Türkçesinde ve Azeri Türkçesinde kullanılan "su unsurlu atasözleri” E.Kemal Eyüboğlu'nun “On Üçüncü yüzyıldan Günümüze Kadar Şiirde ve Halk Dilinde Atasözleri ve Deyimler'- Atasözleri-I, Metin Yurtbaş'ın “Sınıflandırılmış Türk Atasözleri”, Azeri Türkçesinde ise "Celal Beydilli’nin “Atalar Sözü”, Mehman Musaoğlu ve 
Muhittin Küçük” ün, “Açıklamalı Azerbaycan Atasözleri”, Xaliq Rzayev’in, “Atalar Sözü”, gibi eserlerinden seçilmiştir.

\section{2. İşletme ekleri}

Bir cümlede isimler diğer kelime ve kelime gruplarıyla değişik anlam bağlantıları kurmak için aynı durumda bulunmazlar. İlişkinin durumuna göre ayrı ayrı hallere girerler. İsimler bu durumları anlatırken bazen ek almadan bazen de ismin değişik hal eklerini alarak bir münasebet ifade ederler. Demek ki ismin halleri ismin diğer kelimelerle münasebeti sırasında içinde bulunduğu durumlardır. Her hal, her durum bir münasebet ifade eder, her münasebet ifadesi için isim bir halde bir durumda bulunur (Ergin, 1993: 215).

İşletme eklerinden olan bu isim çekim ekleri cümleden çıkarıldığı zaman cümlenin anlamında bir daralma ve bir bozulma söz konusu olacaktır. O nedenle bir fikri veya bir düşünceyi ifade etmede yapım eki ne kadar önemli ise işletme ekleri de o derece önemlidir.

Çekim eklerinin kullanılış alanları yapım eklerinden de öteki işletme eklerinden de daha kapsamlıdır. Ad kök ve gövdelerine de fiil kök ve gövdelerine de gelebilirler (Korkmaz, 2003: 23). Bu bakımdan işletme eklerinin ve o cümleden isim çekim eklerinin kullanımı bir cümlede kelimeler arasındaki anlam ilişkisi ve cümlenin işlerliği bakımından son derece önem arz etmektedir. Dünyada anadilde konuşulan diller arasında ilk sıralarda yer alan Türkçemizdeki atasözlerinde de işletme ekleri geniş bir kullanımda olduğunu görmekteyiz.

\subsection{Ata sözlerinde yalın halde kullanılmış "su" kelimesi}

İsim yada isim soylu kelimenin her hangi bir isim çekim eki almamış halidir. Bir cümlede bir isim çoğul ve iyelik eklerini almış olsa da yalın durumdadır. Kimi atasözlerinde "su" kelimesinin nominatif (yalın) halde kullanıldığını görmekteyiz. Bu hal, gerek Türk gerekse Azerbaycan Türkçelerinde kullanılan su unsurlu atasözlerinde sıkça yer almıştır.

Türkiye Türkçesinde: Acı acıyı, su sancıyı, Aramızdan su sızmaz, Arığa su gelene dek kurbağanın gözü patlar, Ateşle su bir arada olmaz, Ateşle su hatıra bakmaz, Bana iki taş arasından su gelir, Dolu testiye su konmaz, Ekmek elden, su gölden, Her kazılan yerden su ç1kmaz,

Azerbaycan Türkçesinde: Su axar çuxuru tapar, Axar su murdarlıq götürməz, Bulaşıqlı səhəngdən bulanıq su tökülər, Borc su dəyirman dolandırmaz, Hər su keçid verməz, İsti aşa soyuq su qatılmaz, Yol böyüyün, su kiçiyindir, Su murdarlıq götürmez, Su yatar, düşman yatmaz.

Yukarıdaki örneklerde de görüldüğü gibi Türk ve Azerbaycan Türkçelerinde kullanılan su unsurlu atasözlerinde yer alan "su" kelimesi yalın haldedir. Diğer bir husus ise Türkiye Türkçesinde söylenmiş “Acı acıyı, su sancıyı” atasözünün eksiltili cümle şeklinde 
yer aldığını görüyoruz. Bu kullanım Türkiye Türkçesinde söylenmiş diğer atasözlerinde de sıkça karşılaşılan bir durumdur. Azerbaycan Türkçesinde eksiltili cümle şeklinde söylenen atasözlerine nadir rastlanır. Bizce böylesi bir kullanım dilde kolaylığın sağlanmasından ve pratikliğin öne çıkmasından kaynaklanmaktadır.

\subsection{Ata sözlerinde genitif (ilgi) halinde kullanılmış "su" kelimesi}

$\mathrm{Bu}$ hal isimlerde sıkça kullanılan işletme eklerinden biridir. Aynı zamanda tamlama eki olarak da isimlendirilmektedir.

İlgi hali ismin bir isimle ilgisi olduğunu, kendisinden sonra gelen bir isme tabi bulunduğunu gösterir. İsmin bu hali bazen eksiz, çok defa ise ekli olur. Bu ek ismi esas itibariyle isme bazen de fiile bağlar (Ergin, 1993: 216).

Bugün ilgi hali ekinin değişik kelime ilişkilerinde kullanıldığını görmekteyiz. Bu ek üç yerde kullanılmaktadır. Bunlardan ilki ismi isme bağlamaktadır. Ekin asıl işlevi de budur. İkincisinde ilgi hali eki zamirleri bazı edatlara bağlar: benim gibi, senin gibi vb. Üçüncüsü ise ilgi hali eki isimleri fiile bağlar (Vural-Böler, 2011: 163). Bu kelimeler arasında ilgi hali ekinin esas görevi isimler arasında ilişkiyi daha belirgin hale getirerek bir ismi bir başka isme bağlamaktır. Genitif hal Türk ve Azerbaycan Türkçelerindeki atasözlerinde "su" kelimesinin genitif halde kullanılmasına ait örneklere bakalım:

Türkiye Türkçesinde: Bir içim suyun yedi adım yol hakkı vardır, Suyun sessiz akanı, Suyun çağlamazı, insanın söylemezi, Tavşanın suyunun suyu, İnsanın söylemezinden suyun şarlamasından korkulur.

Azerbaycan Türkçesinde: Suyun lal axanından, adamın yerə baxanından, Suyun yavaşından qorx, Suyun əvvəli bulantı gələr,

İncelediğimiz "su” unsurlu atasözlerinde Azerbaycan Türkçesinde kullanılan ilgi eki şeklinin daha seyrek kullanıldığını görmekteyiz.

\subsection{Ata sözlerinde datif (yönelme) halinde kullanılmış "su" kelimesi}

Datif hal eki genelde ismi isme değil; ismi fiile bağlar. Bunun yanında datif ekinin ismi edatlara bağladığı da "sınıfa doğru" görülmektedir. Datif eki burada edatlara bağlansa da asıl amaç edatları da fiile bağlamaktır. İsmi fiile bağlayan ve genellikle fiilin kendine doğru yöneldiğini, yaklaştığını belirtmek için ismin girdiği durumdur (Ediskun, 1996: 111). Fiilin istikametini ve yönünü gösteren aynı zamanda yaklaşma ifade eden bu ek her zaman eklidir. Gerek Türkiye Türkçesinde ve Azerbaycan Türkçesinde sıkça kullanılan eklerden biridir.

Türkiye Türkçesinde: Ağustosta suya girse balta kesmez buz olur, Aldı sattı, suya battı, Balık isteyen, gönlünü suya koyar, Cadı suya batmaz, Eşek ya oduna işler, ya suya, 
Köye gidenin köpeği, suya gidenin susağı, Malın iyisi suya yakın, daha iyisi eve yakın, Oda inanma, suya dayanma.

Azerbaycan Türkçesinde: Dəvəni andılar- ya suya, ya oduna, Könlü balıq istəyən qurşağacan suya girər, Məni aparan suya dərya deyirəm, Nə dərin suya gir, nə Xıdır Nəbini çağır, Şor yeyən suya gələr, Yoxsul yoxsul, oduna, suya da yoxsul?, At suya baxar, su ata, Suya susuz aparıb susuz gətirər.

Yukarıdaki örneklerde de görüldügü gibi Türkiye Türkçesinde ve Azerbaycan Türkçesinde kullanılan datif eki "su” unsurlu atasözlerinde sıkça kullanıldığını görmekteyiz.

\subsection{Ata sözlerinde akkuzatif (yapma hali) halde kullanılmış "su" kelimesi}

Akuzatif eki, fiilin doğrudan tesir ettiği isimlerdir. Fiilde

anlatılan iş oluş ve hareketi isme bağlayan geçişli fiillerdir.

Batı Türkçesinde Azeri sahasında Eski Türkçede olduğu gibi akuzatif ekinin zamirleri bazen edatlara da bağladığı görülür: seni tek "senin gibi”, onu kimi “onun gibi” (Ergin, 1993: 221) misallerinde olduğu gibi.

İsmi daha belirgin hale getiren ve fiile bağlayan bu hal eki Türk ve Azerbaycan atasözlerinde işlek olarak kullanılmıştır. Akkuzatif halde kullanılmış "su" kelimesi atasözlerinde doğrudan nesne görevindedir. Bu türlü atasözlerindeki "su” kelimesi direkt olarak geçişli fiillere aittir. Geçişli fiiller ise nominatif halde olan sözlerle kullanılamaz.

Türkiye Türkçesinde: Akıllı suyu arayıncaya dek deli, suyu geçer, Gemiyi duvarda, suyu bardakta, Suyu görür susar, atı görür aksar, Suyu üfürür de içer.

Azerbaycan Türkçesinde: Ağac böyüdükcə suyu çox aparar, Balıq tutan suyu bulanıq istər, Dəni ellərdən, suyu göllərdən, Haqq söz axar suyu saxlar,

Her iki Türkçede de "su" unsurlu atasözlerinde akkuzatif halde kullanım yer almaktadır.

\subsection{Atasözlerinde lokatif (bulunma) halinde kullanılmış "su" kelimesi}

Cümlede ve kelime gruplarında lokatif hal iş oluş veya hareketin yapıldığı yeri gösterir. O nedenle bir bulunma, kalma anlamı taşır. Lokatif hal cümlede daima ek alarak bulunur.

Lokatif hal esas olarak bulunma bildirir. Bunun yanında yer, zaman, iş, devamlılık, müddet, tarz, şekil, durum, karşılaştırma, kesir, konu, vasıta, gaye, sebep, vasıf, miktar, belirtme, kısım, parça vs. (Ergin, 1993: 223) gibi konuları da içerir.

Azerbaycan Türkçesinde lokatif eki ünsüz uyumuna tabi değildir. O nedenle bu ekin tonsuz şekli yoktur. Ancak bu ek Türkiye Türkçesinde ünsüz uyumuna tabi olarak her iki 
şekilde de kullanılır. Lokatif haldeki "su” kelimesi atasözlerinde genelde dolaylı tümleç görevindedir. Gerek Türk gerekse Azerbaycan Türkçelerinde kullanılır.

Türkiye Türkçesinde: He ördek, he değirmen, ikisi de suda yürür, Asılacak, suda boğulmaz, Aşık, kilimini suda bırakır, Balık avlayanın gözü suda gerek, Bulanık suda balık avlar.

Azerbaycan Türkçesinde: Suda boğulan ilana sarılar, Dəryada balıq sevdası, Suda yağ olsa qurbağa kökələrdi, Suda həyat var, Odda yanmaz, suda batmaz.

Lokatif halde kullanılmış "su” kelimesi Azerbaycan ve Türkiye Türkçesinde mekan anlayışı ifade etmiştir. Burada iki Türkçede de kullanılarak benzerliğin olduğunu görüyoruz.

\subsection{Ata sözlerinde ablatif (ayrılma) halinde kullanılmış "su" kelimesi}

Kelime gruplarında ve cümlede fiilde anlatılan hareketin fiilden uzaklaştı̆̆ını gösterir. Ablatif hal cümlede daima ekli şekilde bulunur. Ana fonksiyon fiilden uzaklaşmayı ifade eder. Ancak bunun yanında: çıkma, yer, uzaklaşma, vasıta, zaman, yokluk, sebep, tarz, ölçü (Ergin,1993: 224) gibi konuları da içerir.

Azerbaycan Türkçesinde ablatif eki ünsüz uyumuna tabi değildir. O nedenle bu ekin tonsuz şekli yoktur. Ancak bu ek Türkiye Türkçesinde ünsüz uyumuna tabi olarak her iki şekilde de vardır. Her iki Türkçenin atasözlerinde bu ek kullanılmaktadır. Ablatif hal cümlede dolaylı tümleç görevindedir.

Türkiye Türkçesinde: Arap atının yanında duran ya huyundan, ya suyundan, Dibi görünmeyen sudan geçme, Dümen suyundan ayrılma, Her şey sudan hayat buldu, Arap atının yanında duran ya huyundan ya suyundan.

Azerbaycan Türkçesinde: Acın zəhləsi sudan gədər, Oddan, sudan yenə qar amannıdı, Sudan ayrılan balığın oddan nə qorxusu?

Azerbaycan Türkçesinde ablatif ekinin "su" unsurlu atasözlerinde daha seyrek kullanıldı̆̆ını görmekteyiz.

Türkçede kullanılan en önemli kelime gruplarından biride tamlamalardır. Tamlamalar bir dilde isimlerin aidiyet duygusunu daha belirgin hale getirmek ya da bir ismin vasfinı ve niteliğini belirtmek için yapılır.

Birden fazla ismin iyelik(aitlik), tahsis, tür, cins ve özellik ifade etmek üzere bir araya gelmesinden hasıl olan birleşik sözlere isim tamlaması (Bilgegil, 1984: 116) denir. Kelime grupları, bünyesinde birden fazla kelime bulunduran, yapı ve anlam bakımından bir bütünlük gösteren, cümlede de bir bütün olarak kullanılan ve herhangi bir yarg1 bildirmeyen dil birlikleridir (Doğan, 2012: 3 ). Birden fazla sözcügün bir araya gelerek üstlendiği görev bir kelimenin üstlendiği görevdir. Bu birleşmelerde tamlayan önce tamlanan ise sonra gelir. $\mathrm{Bu}$ tür kullanımlar Türk ve Azerbaycan Türkçelerinde anlatıma zenginlik katarlar. Türkçede 
kelime gruplarının yer aldığı kullanımlardan biride atasözleridir. Türkçe, sıkça tamlamaların kullanıldığı zengin dillerden biridir. $\mathrm{Bu}$ bakımdan su unsurlu Türk ve Azerbaycan atasözlerinde isim tamlamalarına ve sıfat tamlamalarına sıkça rastlarız.

\section{Belirtili İsim Tamlaması}

İsim soyundan iki veya daha çok kelimenin bir nesne, olay veya hareketin başka bir nesne veya şahsa ait olduğunu bildirmek üzere sistemli bir şekilde bir araya gelmesiyle oluşan kelime grubuna isim tamlaması (Doğan, 2012: 6) denir. Bu tamlamanın amacı, ismin aidiyet duygusunu arttırma ve ismi daha belirgin hale getirmektir. Belirtili ad tamlamalarının birinci tarafı genitif haldedir. Belirtili ad tamlamaları cümlenin birleşik ögesi olur.

Türkiye Türkçesinde: Suyun sessiz akanı, Dağdaki tavşanın suyu ocağa vurulmaz, Yel değirmeni anladık, ama suyu nereden gelir? Yeni testinin suyu ayaz olur, Olursa aşım suyu, olmazsa başım suyu, Karnının huyunu bilen üzümün suyunu içmez, Susuza suyun sesi bülbül sesinden ehvendir.

Azerbaycan Türkçesinde: Anladıq- yel dəyirmanı, bəs bunun suyu hanı?, Dəmyənin bir Allahı var, sulunun iki, İçdim üzüm suyunu, tökdüm üzümün suyunu, Olar aşımın suyu, olamaz başım suyu, Suyun əvvəli bulantı gələr, Suyun lal axanından, adamın yerə baxanından, Suyun yavaşından qorx.

Yukarıdaki örneklerde de görüldüğü gibi gerek Türkiye Türkçesinde gerekse Azerbaycan Türkçesinde kullanılan "su" unsurlu atasözlerinde belirtili isim tamlaması sıkça yer almaktadir.

\subsection{Belirtisiz İsim tamlaması}

Tamlayanın ilgi eki almayıp tamlamanın iyelik eki aldığı tamlamadır. Fakat bu tamlamanın tamlayan tarafina ilgi eki getirerek belirtili isim tamlaması yapılabilir; ancak tamlamanın esas anlamı kaybolur.

Belirtisiz isim tamlamasında, tamlayan ilgi hâli eki almasa da tamlamayı oluştururken tamlanana olan bağlılı̆̆ ve ilgisi belirtili isim tamlamasına oranla daha kuvvetlidir. Bu ilgi, aynı zamanda süreklidir (Doğan, 2012: 16). Belirtisiz isim tamlamaları tamlayanla tamlanan arasına herhangi bir kelime girmez. Belirtisiz isim tamlamalarının birinci tarafindaki "su" kelimesi yalın haldedir.

Türkiye Türkçesinde: Su kuşu talim istemez, Su testisi suyolunda kırılır, Deniz suyu içilmez, Doğruluk, su kapağıdır, batmaz, Su üstünde nakış durmaz, Kulağına kar suyu kaçtı, Yüz suyu ile değirmen dönmez.

Azerbaycan Türkçesinde: Hər kəsin bir dərdi var, dəyirmançının da su dərdi, Su sənəyi suda sınar, Su şərşənbəsində suya gedərlər, Bulanıq suda balıq tutur, Elə bil ürəyinə su səpdilər, Üstünə mürdəşir suyu tökülsün, Boğazından bir qaşıq su keçmir. 
Belirtili isim tamlamasının yanında belirtisiz isim tamlaması da "su" unsurlu Türk ve Azerbaycan atasözlerinde sıkça yer almaktadır.

\section{Sifat Tamlaması}

Atasözlerinde rastladığımız "su" unsurlu ifadelerin bir kısmı takısız isim tamlaması şeklindedir. Türkoloji literatürde takısız isim tamlamalarına sıfat tamlaması denmektedir. Sıfatlar bir ismin vasfinı ya belirtir ya da niteler. O nedenle sıfatlar varlıkların değil vasıflarının adlarıdır.

Sıfatlar isimlerin bir niteliğini, bir özelliğini belirtmek üzere bir isimle birlikte kullanılırken tamlama meydana getirir. Bir isimle birleşen sıfatın oluşturduğu bu kelime grubuna sıfat tamlaması (Vural-Böler,2011:203 ) denir. Sifatlar bir ismi nitelemedikleri zaman, yani tek başına kullanıldıklarında isim olurlar. Bu manada sıfatlar da bir bakıma isimdir. Sıfatlar çekimsiz kelimelerdir. İşletme eklerini aldıkları zaman isimleşirler. İsimler çok yönlü olması nedeni ile bir isim birden fazla sıfat alabilir. Sıfat tamlamasında tamlayan birden fazla olabilir.

Türkiye Türkçesinde: Akan sular durulur, Akarsular bulanır, Bir kaşık suda boğmak ister, Susuz ağaç meyve vermez, Susuz çöl, ormansız dağ, Sulu kuleye gider de susuz gelir.

Azerbaycan Türkçesinde: Axar su gedər, qalmaz, Axar su murdarlıq götürməz, Bir su ki girdi qaba, oldu içməli, Məni aparan suya dərya deyirəm, Borc su dəyirman dolandırmaz, Bulaşıqlı səhəngdən bulanıq su tökülər.

Örneklerde de görülüyor ki, bazı tamlamaların belirleyen tarafı (sulu kule, sudaki balık, susuz ağaç, susuz çöl), bazılarında belirtilen tarafı (akan su, akarsu, bir kaşık su, dökülen su, dibi görünmeyen su) "su” kelimesinin yardımıyla oluşmuştur. Sıfat tamlaması da diğer tamlamalar gibi her iki Türkçede de yer almaktadır.

Türkiye Türkçesinde sıfat tamlamaları aynı zamanda basit ve türeme olabildiği halde, Azerbaycan Türkçesinde sıfat tamlamaları sadece basit sözlerden oluşur. Bu farklılık kendini daha çok yazılı metinlerde göstermektedir.

Azerbaycan Türkçesinde bu tip cümlelerin birinci tarafını, yani belirten tarafını ayrıca bir cümle öğesi olarak kabul edilir. Türkiye Türkçesinde ise, birinci taraf ikinci taraftan ayrı şekilde düşünülemez. Örneğin: Borc su dəyirman dolandırmaz (Azerbaycan Türkçesi) atasözünde "borç su” ifadesi ayrı şekilde alınır: dolandırmaz (yüklem), sudolandırmaz (özne), hangi su? Borç (belirten); ney dolandırmaz- dəyirman (nesne).

Susuz ağaç meyve vermez (Türkiye Türkçesi). Susuz ağaç (özne); vermez(yüklem), meyve(nesne). 


\section{Ata sözlerinde "su" kelimesinin cümle ögeleri fonksiyonları}

Bir duyguyu, bir düşünceyi tam olarak ifade eden söz yada söz topluluğuna cümle denir. Cümleyi oluşturan esas unsur çekimli bir fiilin veya ek eylem almış bir ismin yüklem olmasidir.

Bütün dillerde söz dizimi, varlıkların nitelendirildiği yapılar olan söz öbekleri ile yapma ve olmaların nitelendiği yapılar olan cümlelerden oluşur (Karaağaç, 2011: 220). Bir kelimeden cümlenin oluşabileceği gibi birden fazla söz öbeklerinin bir araya gelmesiyle de cümle olabilir. Önemli olan kelimenin çokluğu değil; onun bir yargı, bir hüküm bildirmesidir.

Yani cümle, değişik işlevlerdeki parçalardan meydana gelmiş bir bütündür. İşte cümleyi oluşturan bu parçalara cümlenin ögeleri (Özkan, 2013:8)denir. Cümlenin asıl öğelerini belirleyen, onları izah eden öğe yardımcı öğedir (Rüstemov, R.E.; Şireliyev, M. Ş.; Budagova, Z. İ. 1959: 118). Cümlenin yardımcı ve asıl ögelerinin amacı yüklemin anlamını tamamlamaktır. Türk ve Azerbaycan Türkçelerinde kullanılan su unsurlu atasözlerinde "su" kelimesi cümlenin değişik ögesi olarak kullanılmıştır.

\section{1. Özne}

Cümlede iş oluş ve hareketi yapandır özne. Cümlenin en önemli asıl ögelerinden biridir. Özne cümlede isim ya da isim grubundan olan kelime olabilir. Ayrıca özne, cümlede yalın halde bulunur.

Gerçek öznesi bulunmayan, geçişli eylemlerin edilgen çatılarıyla kurulan tümcelerde, özne olmadıkları halde, özne görünümündeki ögelere sözde özne adı verilir. Sözde özneler işi yapan değil, işten etkilenen olmaları bakımından nesneye daha yakındır (Eker, 2005: 454). Özne cümlede ya açık şekilde bulunur ya da yüklemde şahıs eki şeklinde bulunur. Öznesi olmayan cümlelerde vardır. Bunlar geçişsiz fiillerin cümlede yüklem olduğunda ve gereklilik kipinin üçüncü tekil şahsında olur.

Zamirler dahil her eksiz isim soylu, özne olabilir. Özne yüklemden sonra, yüklemin bir parçası olarak ifade edilebilir (Gabain, 1988: 120).

Türkiye Türkçesinde: Aramızdan su sızmaz, Suyu akarına giden yorulmaz, Dolu testiye su konmaz, Süt katılan sular ineği götürdü, Yel üfürdü, su götürdü.

Azerbaycan Türkçesinde: Axar su gedər, qalmaz, Axar su murdarlıq götürməz, Borc su dəyirman dolandırmaz, Dayanan su tez iyiyər, Dərin su bulanmaz.

Yukarıdaki örneklerde her iki Türkçede de "su” kelimesinin cümlede özne olduğunu görüyoruz. 


\subsection{Yüklem}

Yüklem, cümlenin en önemli ögelerinden biridir. Bir cümlede nesne veya tümleç olmayabilir, ancak yüklem mutlaka bulunur. Yüklemsiz cümle olmaz. Yüklem, cümlede iş oluş veya hareketin tamamlandığı, bir yargıya bağlandığı ögedir.

Yüklem yargının, dolayısı ile cümlenin düğümlendiği kelimedir. Cümlenin cinsini de onun yapılışı belli eder (Banguoğlu, 1995: 525). Türkçede asıl unsurun tali unsurdan sonra gelmesi prensibine uygun olarak, cümlenin esas unsuru olan fiil daima sonda bulunur (Ergin, 1993: 377). Cümlede yer alan diğer ögeler için böyle bir ölçü yoktur. Aynı zamanda cümlede vurgulanmak istenen öge yükleme yakın şekilde yer alır. Gerek Türkiye Türkçesinde gerekse Azerbaycan Türkçesinde yüklemin kullanımı aynı gerekçelere dayanmaktadır. Her iki Türkçede de kullanılan su unsurlu atasözlerinde "su" kelimesi yüklem olarak kullanılmıştır.

Türkiye Türkçesinde: Un kodum ulandı, su kodum sulandı, Ayranım budur, yarısı sudur, Buğday katında acı ot da sulanır, Deniz kenarında susuz kaldım.

Azerbaycan Türkçesinde: Biri od olanda biri su olsun gərək, Həmi ulaq, həmi sulaq, Həya üzdə bir qətrə sudur, At görəndə axsayır, su görəndə susayır.

Her iki Türkçede de "su” unsurlu atasözlerinde "su” kelimesinin yüklem olarak kullanılması sık karşılaşılan bir durum değildir.

\subsection{Nesne}

Nesne, cümlede yüklemde anlatılan işten etkilenen ögedir. Cümlede fiiller geçişli ve geçişsiz olmak üzere iki şekilde bulunur. Geçişli fiiller yüklemde anlatılan işi nesneye yükler, geçişsiz fiiller ise özneye yükler. Geçişli fiillerin etkilendiği nesne akuzatif halinde bulunur.

Eğer cümlede nesne belirtme hali ekini almışsa, bu nesnelerin anlamlarında "varlığın belli, bilinir olduğu" ifade edilmiştir. Eğer nesne eksiz halde ise "varlığın genel, herhangi bir varlık olduğu" bildirilmiştir (Göker, 1997: 73). Aynı zamanda cümlede kullanılan kelime grupları da belirtme ekini alması durumunda nesne görevini üstlenebilir. Türkiye Türkçesinde ve Azerbaycan Türkçesinde kullanılan su unsurlu atasözlerinde su kelimesi nesne olarak kullanılmıştır.

Türkiye Türkçesinde: Yem istemez, su istemez, Ebe teknesinden beri su görmemiş, Beylik çeşmeden su içme, Çömlekçi suyu testiden içer, Dimyat pirincidir, çok su kaldırır, Saman altında su yürütür.

Azerbaycan Türkçesinde: Balıq tutan suyu bulanıq istər, Dəyirmana su hardan axdığın öyrən, İsti aşa soyuq su qatmazlar, Könül gözdən su içər, Bu aş çox su aparar, Suyu üfüre-üfüre içir.

Azerbaycan Türkçesinde ve Türkiye Türkçesinde "su" unsurlu atasözlerinde "su" sözcüğü nesne olarak sıkça kullanılır. 


\subsection{Zarf}

Zarf cümlede yüklemin anlamını zaman, durum, miktar, soru ve yer-yön bakımından tamamlayan ögedir. Zarflar fiillerin sıfatlarıdır. O nedenle zarflar yükleme, yani fiile yakın olurlar. Zarf tümleci olan kelime isim ve isim cinsinden bir kelimedir. Bunun yanında zamirler ve ünlemler zarf tümleci olarak kullanılmaya elverişli değillerdir (Göker, 1997:78). Zarf olan kelime mutlaka fiili niteler ve yalın durumda bulunur.

Yapma ve olmaları niteleyen her türlü söz ve yapı zarftır (Karaağaç, 2010: 235).

Türkiye Türkçesinde: Arığa su gelene kadar kurbağanın gözü patlar, Denizin kenarında susuz kaldım, Suyu görmeden çemrenme, Tavuk bile su içerken göge bakar, Su akarken testiyi doldur.

Azerbaycan Türkçesinde: Arxa su gələnəcən Hamam suyu ilə xətir- göyül görür.qurbağanın canı çıxar, Balıq sudaykən sövda olmaz, Oddan, sudan yenə qar amanlıdır, Su meymunun boğazına çıxanda balasını ayağı altına alar.

Türkiye Türkçesinde ve Azerbaycan Türkçesinde kullanılan "su” unsurlu atasözlerinde zarf tümlecinin kullanımı yaygındır.

\subsection{Dolaylı Tümleç}

Cümlede fiilin anlatmış olduğu işin yerini ve yönünü gösteren ögeye denir. Dolaylı (yer) tümleç cümlede ismin -e, -de, -den halinde bulunur. Bu terimdeki yer kavramının içinde bulunma, yönelme, uzaklaşma, ayrılma, karşılaştırma, verme, değiştirme, sebep, miktar, derece, durum, konu, görüş gibi anlam ilişkileri vardır (Göker, 1997: 75). Cümledeki fiilde anlatılan her bir hareketin yönü ve yeri vardır. İşte yer tamlayıcısı bu istikameti ve yeri gösterir.

Türkiye Türkçesinde: Balık isteyen gönlünü suya koyar, Yelkenleri suya erdi, Deveyi dügüne ya suya, ya da oduna göre davet ederler, Derin suya girdiysen Hızır'1 çağıracaksın.

Azerbaycan Türkçesinde: Balığın dirisi də suda, ölüsü də, Balıq suya çəkər, Dəvəni andılar- ya suya, ya oduna, Nə dərin suya gir, nə Xıdır Nəbini çağır.

Türkiye Türkçesinde ve Azerbaycan Türkçesinde kullanılan "su” unsurlu atasözlerinde yer tamlayıcısı sıkça kullanılmıştır.

\section{Sonuç}

Aynı grupta (Oğuz) yer alan Azerbaycan Türkçesinde ve Türkiye Türkçesinde kullanılan "su" unsurlu atasözlerinde yapmış olduğumuz bu çalışmada benzer gramer 
uygulamaların yanında farklı gramer uygulamaların da olduğunu görmekteyiz. Bu hususları şöyle siralayabiliriz.

Türkiye Türkçesinde kullanılan "su" unsurlu atasözlerinin birinci tarafı basit ve türemiş sözlerle ifade edilebildiği halde Azerbaycan Türkçesinde "su" unsurlu atasözlerinde geçen sıfat tamlamalarının birinci tarafı yalnızca basit sözlerle ifade edilir.

Azerbaycan Türkçesinde tamlamaların birinci tarafı daima ilgi halinde olan sözlerdir. Türkiye Türkçesinde kullanılan tamlamalarda farklı hallere de (yalın ve iyelik) rastlamak mümkündür.

Azerbaycan Türkçesinde "su" unsurlu atasözleri bütün şekilde ifade edilirken Türkiye Türkçesindeki su unsurlu atasözlerinde cümlelerin yüklem eki almadan da kullanılabildiğini yani, eksiltili cümle şeklinde kullanıldığını görmekteyiz.

Türkiye Türkçesinde "su” unsurlu sözler cümlenin nesnesi, öznesi, yüklemi olabilir. Azerbaycan Türkçesinde "su” unsuru aynı zamanda belirten (tayin) rolünde de bulunur.

\section{Kaynaklar}

ABBASLI, İ. (2004 ). Atalar Sözü. Bakü: Önder Neşriyat.

BANGUOĞLU, Tahsin (1995). Türkçenin Grameri. Ankara: TDK Yayınları.

BİLGEGİL, M. Kaya (1984). Türkçe Dilbilgisi, İstanbul: Dergah Yayınları.

DOĞAN, Enfel (2012). Türkçe Cümle Bilgisi. Editörler: Mustafa ÖZKAN, Hülya PİLANCI, Eskişehir: T.C. Anadolu Üniversitesi Yayınları.

EDİSKUN, Haydar (1996). Türk Dilbilgisi. İstanbul: Remzi Kitabevi.

EKER, Süer (2005). Çağdaş Türk Dili. Ankara: Grafiker Yayınları.

ERGIN, Muharrem (1993). Türk Dil Bilgisi. İstanbul: Bayrak Yayınları.

EYÜBOĞLU, E. Kemal (1973). On Üçüncü Yüzyıldan Günümüze Kadar Şiirde ve Halk Dilinde Atasözleri ve Deyimler. İstanbul: Eren Yayıncılık.

GABAİN, A. VON (1988). Eski Türkçenin Grameri. (çeviren: Mehmet AKALIN). Ankara: TDK Yayınları. 
GÖKER, Osman (1997). Uygulamalı Türkçe Dilbilgisi. İstanbul: MEB Yayınları.

HEKİMOV, M. İ. (1986). Halkımızın Deyimleri ve Duyumları. Bakü: Maarif Neşriyyatı.

KARAAĞAÇ, Güney (2011). Türkçenin Söz Dizimi. İstanbul: Kesit Yayınları, 4. Baskı.

KORKMAZ, Zeynep (2003). Türkiye Türkçesi Grameri (Şekil Bilgisi). Ankara: Türk Dil Kurumu Yayınları.

MUSAOĞLU, Mehman; KÜÇÜK, Muhittin (1995). Açıklamalı Azerbaycan Atasözleri. Ankara: Engin Yayınları.

ÖZKAN, Mustafa (2013). Türkçe Cümle Bilgisi II. Editörler: Mustafa ÖZKAN, Hülya PİLANCI, Eskişehir: T.C. Anadolu Üniversitesi Yayınları.

RÜSTEMAV, R. A; ŞİRELIYEV, M. Ş.; BUDAGOVA, Z. İ. (1959). Azerbaycan Dilinin Gramatikası. Bakü: Azerbaycan SSR Elmler Akademiyası Neşriyyatı.

RZAYEV, Xaliq (2004). Atalar Sözü. Bakı: Nurlar Neşriyyat.

VURAL, Hanifi; BÖLER, Tuncay (2011). Ses ve Şekil Bilgisi. İstanbul: Kesit Yayınları. YURTBAŞI, Metin (1994). Sınıflandırılmış Türk Atasözleri. Ankara: Özdemir Yayıncılık. 